\title{
THIS LAND IS MINE!: RELATO DE UMA EXPERIÊNCIA GAMIFICADA NA CAPACITAÇÃO DE PROFESSORES EM TDIC
}

\section{This Land is Mine!: report of a gammed experience in DTIC training teachers}

\author{
Karen Cristina Braga ${ }^{1}$ \\ Calebe da Silva Borges ${ }^{2}$ \\ Silvia de Castro Bertagnolli ${ }^{3}$
}

\begin{abstract}
Resumo: Este artigo tem como objetivo descrever um relato de experiência em que uma estratégia gamificada, denominada 'This Land Is Mine!', foi adotada na formação de docentes em TDIC. O seu propósito foi demonstrar aos participantes como a gamificação pode ser aplicada em sala de aula (atendendo a suas dinâmicas, mecânicas e componentes) e como as competências da BNCC podem ser abordadas de modo lúdico. No seu desenvolvimento, foi utilizada a pesquisa bibliográfica para orientar o planejamento da estratégia, além de uma pesquisa-ação, que contou com 12 participantes do Instituto Federal de Educação, Ciência e Tecnologia do Rio Grande do Sul - IFRS vinculados ao Mestrado Profissional em Informática da Educação - MPIE, que tem entre seus propósitos a formação de docentes. Além disso, o estudo ainda incluiu coleta de dados por meio de questionário e avaliação, através de um momento de reflexão, bem como observação do ambiente da prática pedagógica realizada. Como resultados, pode-se perceber que a gamificação, para ser aplicada em sala de aula, deve ser bem planejada, e que, embora várias tecnologias tenham sido utilizadas na experiência, as atividades que foram melhor avaliadas foram as que envolveram criatividade, trabalho em equipe e colaboração.
\end{abstract}

Palavras-chave: Formação de Professores. TDIC. Gamificação.

Abstract: This paper aims to describe a gamified strategy experience called 'This Land Is Mine!" using teacher training on DTIC. The goal was to show to the participants how gamification can be applied in the classroom (attending dynamics, mechanics, and components), and how BNCC (Brazilian National Common Curricular Base) can be approached in a ludic way. The paper development used bibliographic research to guide the gamified strategy, and an action-research with 12 people from the Instituto Federal de Educação, Ciência e Tecnologia do Rio Grande do Sul - IFRS enrolled in the master's course Mestrado Profissional em Informática da Educação - MPIE, which has, among its purposes,

\footnotetext{
${ }^{1}$ Mestre em Informática na Educação pelo Instituto Federal do Rio Grande do Sul - IFRS (2020), pós-graduada em Informática na Educação pela Universidade Feevale (2008), e bacharel em Informática, ênfase: Análise de Sistemas pela Universidade do Vale do Rio dos Sinos - Unisinos (1999). Orcid: https://orcid.org/0000-00033866-7268. E-mail: karencbraga@gmail.com.

${ }^{2}$ Mestrando do Mestrado Profissional em Informática na Educação do Instituto Federal de Educação, Ciência e Tecnologia do Rio Grande do Sul (IFRS). Orcid: https://orcid.org/0000-0003-4685-4899. E-mail: calebebores@gmail.com.

${ }^{3}$ Doutora em Computação pela Universidade Federal do Rio Grande do Sul (2004). Professora Orientadora do Mestrado Profissional em Informática na Educação. Instituto Federal de Educação, Ciência e Tecnologia do Rio Grande do Sul - Campus Porto Alegre - RS / Brasil. Orcid: https://orcid.org/0000-0001-7495-6636. E-mail: silvia.bertagnolli@poa.ifrs.edu.br
} 
teacher training. Moreover, the study included data collection using questionnaire and evaluation through a moment of reflection, in addition to environment observation through the pedagogical practices performed. As a result, it can be seen that gamification, to be applied in the classroom, must be well planned; and that, although several technologies have been used in the experiment, the activities that were best evaluated were those that involved creativity, teamwork, and collaboration.

Keywords: Teacher training. DTIC. Gamification.

\section{Introdução}

O reconhecimento das Tecnologias Digitais da Informação e Comunicação (TDIC) na sociedade contemporânea e seus reflexos nos processos de ensino e de aprendizagem têm impactado diversas regulamentações e documentos norteadores da área de educação. Considerando-se a educação básica em especial, as Diretrizes Curriculares Nacionais da educação básica (DCNs) (BRASIL, 2013) destacam que "O conhecimento científico e as novas tecnologias constituem-se, cada vez mais, condição para que a pessoa saiba se posicionar frente a processos e inovações que a afetam." (BRASIL, 2013, p. 26). Esse documento ainda aponta o uso de TDIC para propiciar ambientes de aprendizagem mais dinâmicos, e indica que elas podem ser adotadas como recursos para qualificar currículos, de modo que "perpassem transversalmente a proposta curricular desde a Educação Infantil até o Ensino Médio" (BRASIL, 2013, p. 33). Da mesma forma, a Base Nacional Comum Curricular (BNCC) (BRASIL, 2017), também vinculada à educação básica, indica em suas Competências Gerais (CG) a importância das TDIC, estabelecendo, além do seu uso, que os estudantes possam atuar na criação de tecnologias, visando à comunicação, à resolução de problemas, ao acesso e à disseminação de informações, entre outras atividades.

Embora essas normatizações apontem que as TDIC devem ser integradas à prática docente, é necessário prever a formação de professores, de modo a promover aspectos teóricos, metodológicos e pedagógicos relacionados à aplicação das TDIC em sala de aula (BRASIL, 2013). Ao proceder a uma busca na literatura por trabalhos relacionados, nota-se que o uso de metodologias ativas da aprendizagem tem se destacado como uma prática pedagógica para este fim. Pesquisas desenvolvidas por Brito e Viana (2019); Arruda et al. (2019); Vieira e Andrade (2019); e Bastos e Siqueira (2019) abordam o uso de metodologias ativas na formação de docentes, usando design thinking, sala de aula invertida, aprendizagem por pares, aprendizagem em equipe e gamificação.

Nesse contexto, a aprendizagem por meio de histórias e jogos tem se destacado (BACICH; MORAN, 2018), porque viabiliza a inclusão de situações do cotidiano dos alunos na sala de aula através de jogos digitais, potencializando a aprendizagem em diversas áreas do conhecimento (GONÇALVES, 2016). Da mesma forma, a gamificação tem favorecido processos de ensino e de aprendizagem nos diversos níveis de ensino (BACICH; MORAN, 2018). Ogawa et al. (2016, p. 440) definem gamificação como um "termo utilizado para definir a utilização de elementos e design de jogos em contextos não lúdicos a fim de estimular e motivar seus usuários a alcançarem objetivos específicos."

Diante desse contexto, este trabalho tem como objetivo descrever um relato de experiência em que uma estratégia gamificada, denominada 'This Land Is Mine!', foi adotada na formação de docentes em TDIC. O seu propósito foi demonstrar aos participantes como a gamificação pode ser aplicada em sala de aula (atendendo a suas dinâmicas, mecânicas e componentes) e como as competências da BNCC podem ser abordadas de modo lúdico. Os procedimentos metodológicos usados foram a pesquisa bibliográfica, que guiou $\mathrm{o}$ 
planejamento da estratégia gamificada; e uma pesquisa-ação, que contou com 12 participantes do Instituto Federal de Educação, Ciência e Tecnologia do Rio Grande do Sul - IFRS, vinculados ao curso de Mestrado Profissional em Informática na Educação (MPIE), que tem entre seus propósitos a formação de docentes. As etapas selecionadas para guiar a pesquisa foram as definidas pelo ciclo clássico da pesquisa-ação (FILIPPO; ROQUE; PEDROSA, 2019): planejar, agir e refletir.

$\mathrm{O}$ 'This Land Is Mine!' se inspirou nos jogos de tabuleiro clássicos WAR e Monopoly (baseados em conquistas de territórios e bens) e buscou mobilizar o uso de TDIC diferenciadas pelos participantes. As tecnologias selecionadas foram associadas a distintos contextos de aprendizado por meio de desafios, resolução de problemas, conclusão de tarefas, conquistas e interação. O perfil interdisciplinar dos participantes, educadores de diversas áreas do conhecimento, com diferentes níveis de atuação e em níveis variados de domínio das TDIC em sala de aula, favoreceu o desenvolvimento das atividades. A ação ocorreu dentro de um laboratório diferenciado, durante quatros períodos de uma aula que propiciou a observação das interações entre os participantes durante a sua realização. Ao concluir a estratégia gamificada, todos refletiram sobre a ação e responderam a um questionário composto por perguntas abertas e fechadas, o qual permitiu delimitar com quais atividades e ferramentas tecnológicas os participantes demonstraram maior ou menor afinidade.

Este artigo prossegue organizado da seguinte forma: na seção 2, estão os principais conceitos que fundamentam a estratégia gamificada conduzida por este trabalho; a seção 3 aborda o percurso metodológico percorrido, os participantes, a coleta e a análise de dados; a seção 4 descreve quais dinâmicas, mecânicas e componentes foram usados no planejamento; a seção 5 relata como foi o processo de aplicação da gamificação em sala de aula; a seção 6 detalha alguns dos resultados obtidos e a reflexão realizada pelos participantes; e a seção 7 apresenta as considerações finais.

\section{Gamificação}

Instigada pela importância da gamificação em diversas áreas, esta pesquisa se expande para a área da educação, analisando como tal prática pode se tornar uma estratégia de ensino e de aprendizagem (GONÇALVES, 2016). A gamificação é uma metodologia que teve origem no mundo dos negócios, reunindo estratégias e mecânicas de jogos para motivar os envolvidos a atingir objetivos, podendo ser aplicada na educação para aumentar o comprometimento de estudantes (MUZEKA; MARQUARDT, 2017). O processo de gamificação é composto por etapas que executam diferentes atividades e também pode ser definido como "um sistema em que os jogadores se engajam em um desafio abstrato, definido por regras, interatividade e feedback" (KAPP, 2012, p. 7). As regras são fundamentais no planejamento de uma atividade gamificada, pois todo jogo deve prever um regulamento para ser aplicado (HUIZINGA, 2000).

Gamificação é uma maneira de modelar o comportamento, e sua maior contribuição na educação, segundo Alves (2014) e Gonçalves (2016), dá-se na motivação (extrínseca e intrínseca) e no engajamento durante o processo de aprendizagem. A motivação é individual e está inteiramente relacionada a razões pessoais, interesses e exercícios de suas próprias capacidades (DECI; RAYN, 1995); por outro lado, o engajamento envolve tudo aquilo que leva as pessoas a alcançarem um objetivo ou meta, ou seja, demanda um comprometimento e alinhamento a partir de propósitos, visões e interesses em comum (BAKKER et al., 2011). Conforme Vianna et al. (2013) e Alves (2014), a gamificação consiste em usar elementos dos jogos, em contexto de não jogo, para engajar pessoas, motivar a ação, promover a aprendizagem e resolver problemas. Em sua essência, a gamificação é sobre envolver 
(engajar) as pessoas em um nível emocional e motivá-las a alcançar seus objetivos (BURKE, 2016). É importante observar que gamificação não é um jogo, pois, na verdade, compreende a transposição da lógica dos jogos para encorajar atividades (que possam resultar na aprendizagem, por exemplo) usando elementos apropriados (KAPP, 2012). Todavia, para alcançar bons resultados em sala de aula, é necessário o planejamento da operação, considerando objetivos, conteúdos, estratégias e resultados almejados.

No caso da gamificação, três categorias de elementos de jogos podem ser empregadas (WERBACH; HUNTER, 2015): (i) as dinâmicas são elementos abstratos e de alto nível de um sistema gamificado, e são compostas pelo uso de: narrativa, emoções, restrições, progresso e relacionamento (POYATOS NETO, 2015) - neste trabalho, todas essas dinâmicas foram aplicadas, conforme será apresentado posteriormente -; (ii) as mecânicas são responsáveis por conduzir o jogador, motivando-o a agir e a avançar - nesta pesquisa, foram aplicadas cinco mecânicas classificadas por Poyatos Neto (2015): desafio, competição, cooperação, feedback e recompensas -; (iii) os componentes são as peças que compõem as mecânicas do jogo em que os jogadores interagem com o ambiente gamificado - neste trabalho, foram adotados cinco componentes propostos por Werbach e Hunter (2015): missões, conquistas, pontuação, combates e times/equipes.

Poyatos Neto (2015) ressalta que não existem elementos obrigatórios na gamificação; sendo assim, utilizam-se somente os elementos necessários de maneira eficaz, de acordo com a proposta do jogo. Portanto, no planejamento do 'This Land Is Mine!', cada um dos elementos foi analisado, visando a identificar os que mais contribuíram para o processo de ensino e de aprendizagem.

\section{O Percurso Metodológico do 'This Land Is Mine!'}

Este trabalho foi guiado por uma pesquisa-ação sistematizada em três etapas: planejar, agir e refletir (FILIPPO; ROQUE; PEDROSA, 2019). O planejamento foi realizado com o apoio dos aspectos teóricos identificados na pesquisa bibliográfica (GIL, 2008). Com ela, foi possível localizar diversas publicações relacionadas com a formação docente e com o uso de gamificação. Nessa busca, foram identificados alguns mapeamentos sistemáticos da literatura (KITCHENHAM, et al., 2009) relacionados com gamificação, os quais viabilizaram a seleção dos elementos que foram adotados na estratégia:

a) a partir do trabalho de Ogawa, Klock e Gasparini (2016), foi possível identificar os elementos mais utilizados (como medalhas, ranking, pontos e níveis); esses autores apontam que a "maioria dos experimentos incluíram as atividades de exercícios ou tarefas, pesquisas de satisfação e teste para avaliar" a ação;

b) com base no trabalho de Filho, Silva e Inocêncio (2018), percebeu-se que a gamificação pode não ser eficiente se o planejamento não levar em consideração o perfil dos usuários;

c) os autores Toda, Silva e Isotani (2017) destacam que, ao participarem da gamificação, os usuários podem apresentar um comportamento indesejado, tornando-se, em alguns casos, extremamente competitivos; eles ainda apontam algumas ferramentas que podem auxiliar no planejamento e na implantação das atividades;

d) considerando o trabalho de Toda et al. (2018), o mapeamento aponta vários desafios, mas o que foi considerado importante, para o contexto deste trabalho, é o que mostra a "discrepância na quantidade de elementos utilizados entre as abordagens analisadas", o que pode dificultar a compreensão sobre o que é a gamificação. Segundo os autores, 
isso é potencializado, também, porque "diversos desses elementos possuem conceitos similares (por exemplo, conquistas e medalhas, ou ranking e placares)". Eles ainda argumentam que não há necessidade de aplicar todos os elementos previstos no desenvolvimento de uma estratégia.

A partir desses trabalhos e de outros referenciais teóricos que utilizam frameworks para gamificação (KIM et al., 2018), foi possível perceber que o planejamento dos elementos que serão utilizados é essencial, pois, assim como podem engajar, tais aspectos também podem desmotivar a participação dos estudantes. Desta forma, utilizando todo esse contexto, o planejamento da estratégia gamificada 'This Land Is Mine!' foi realizado, como descreve a próxima seção.

\subsection{Planejamento}

Sobreira, Viveiro e Abreu (2020) argumentam que a intencionalidade pedagógica do professor deve conduzir as experiências de aprendizagem. Assim, para iniciar a definição da estratégia gamificada deste trabalho, os autores consideraram que o objetivo principal seria propor experiências diferenciadas de interação dos participantes com as TDIC. As tecnologias foram selecionadas de modo que eles conseguissem perceber como tais recursos poderiam ser aplicados em suas estratégias pedagógicas em sala de aula, e como os professores poderiam abordar as competências gerais da BNCC. Em seguida, os autores previram que os desafios deveriam contemplar diferentes competências e habilidades dos participantes, assim como instigar o uso das TDIC propostas pelo jogo. Também ficou estabelecido que a atividade utilizaria TDIC, mas não seria guiada por ambiente ou ferramenta tecnológica, visto que o tempo para a sua realização era restrito.

As ações planejadas para o 'This Land Is Mine!' foram divididas em dois momentos: a primeira considerou a etapa criativa, e a segunda, as atividades gamificadas, como ilustra a Figura 1. As TDIC empregadas tinham o objetivo de corroborar o fortalecimento das atividades, que foram criadas levando em conta as propostas de Poyatos Neto (2015).

Figura 1 - Etapas do This Land Is Mine!

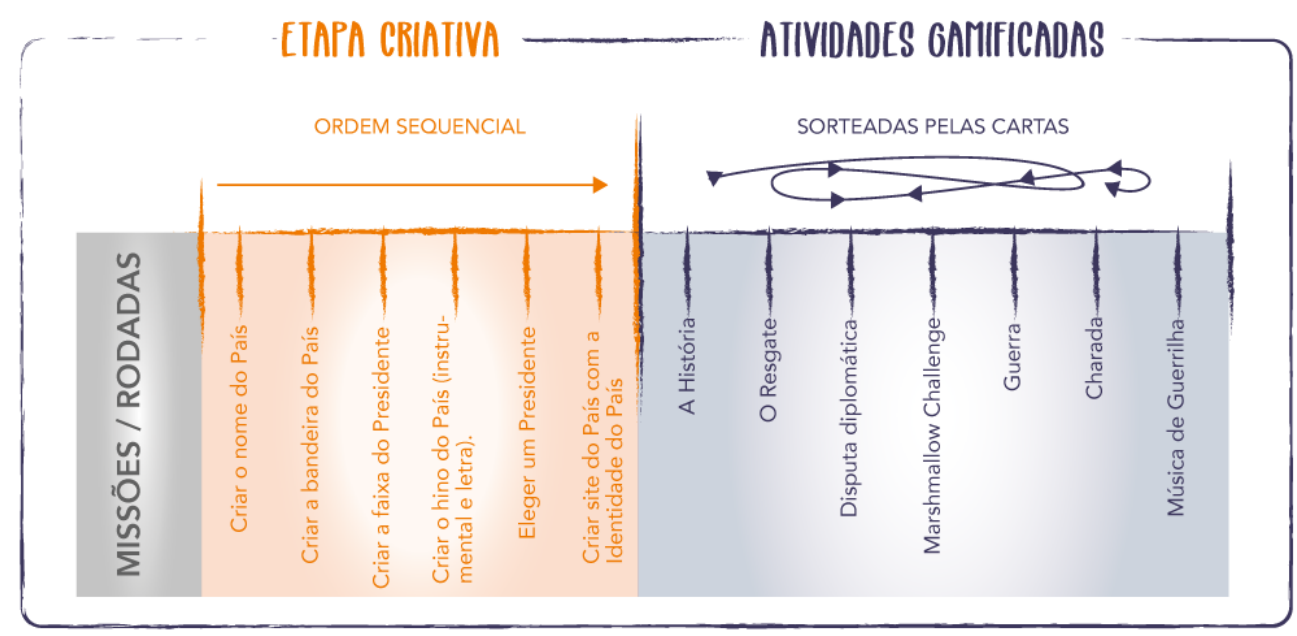

Fonte: Elaborado pelos autores, 2019.

A etapa criativa foi incluída com o propósito de instigar a criatividade dos participantes, estimular diferentes competências e promover a integração das equipes que foram formadas, uma vez que eles tiveram de criar artefatos alusivos a um país imaginário, do 
Revista de Educação, Ciência e Tecnologia

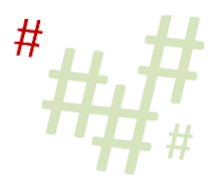

qual eles faziam parte. Essa etapa serviu para demonstrar aos participantes como atividades criativas podem ser aplicadas em sala de aula e como elas podem mobilizar os estudantes.

A proposição da Etapa Criativa é fundamentada na Espiral da Aprendizagem Criativa proposta por Resnick (2017): Imaginar, Criar, Brincar, Compartilhar, Refletir, Imaginar. Esta espiral, segundo o autor, é como o motor do pensamento criativo. Na medida em que os participantes a percorrem, manifestam e aperfeiçoam as habilidades de pensadores criativos. Usando o conceito apresentado e buscando a integração por meio da criação, foi proposto pelos pesquisadores que os participantes desenvolvessem, usando materiais lúdicos, os artefatos utilizados no 'This Land Is Mine!'. O foco dessa etapa foi demonstrar a eles como alinhar a estratégia gamificada às competências gerais da BNCC, em especial a CG 2, que destaca a importância da criatividade para a resolução de problemas: "Exercitar a curiosidade intelectual e recorrer à abordagem própria das ciências, incluindo a investigação, a reflexão, a análise crítica, a imaginação e a criatividade, para investigar causas, elaborar e testar hipóteses, formular e resolver problemas e criar soluções (inclusive tecnológicas) com base nos conhecimentos das diferentes áreas."

Pensando nessas argumentações e nas proposições de Resnick (2017), essa etapa foi incluída com o propósito de explorar a criatividade dos participantes, estimular diferentes competências e promover a integração da equipe, uma vez que eles tiveram de criar artefatos relacionados a um país fictício. Além disso, ela viabilizou aos participantes pensar e se expressar de forma criativa. O Quadro 1 descreve a atividade criativa planejada, as habilidades que se pretendia incentivar e a regra que foi utilizada durante a aplicação da etapa em sala de aula, além de indicar as tecnologias que deveriam ser empregadas para concluir a atividade.

Quadro 1 - This Land Is Mine! - etapa criativa

\begin{tabular}{|c|c|c|}
\hline Atividade & Habilidade(s) & Regra \\
\hline $\begin{array}{l}\text { Criar o nome do } \\
\text { país }\end{array}$ & $\begin{array}{l}\text { Trabalho em equipe, argumentação, } \\
\text { comunicação }\end{array}$ & $\begin{array}{l}\text { Criar um nome que expresse a motivação da equipe em } \\
\text { aprender sobre gamificação. }\end{array}$ \\
\hline $\begin{array}{l}\text { Criar a bandeira do } \\
\text { país }\end{array}$ & Trabalho em equipe, comunicação & $\begin{array}{l}\text { Utilizar materiais como: papel cartolina, papel crepom, cola } \\
\text { de silicone, tecidos TNT, tesouras, grampeador, pincéis } \\
\text { atômicos coloridos e fitas (crepe - larga/fina e cetim). }\end{array}$ \\
\hline $\begin{array}{l}\text { Criar a faixa } \\
\text { presidencial }\end{array}$ & $\begin{array}{l}\text { Trabalho em equipe, comunicação, } \\
\text { criatividade }\end{array}$ & $\begin{array}{l}\text { Utilizar materiais como: papel cartolina, papel crepom, cola } \\
\text { de silicone, tecidos TNT, tesouras, grampeador, pincéis } \\
\text { atômicos coloridos e fitas (crepe - larga/fina e cetim). }\end{array}$ \\
\hline $\begin{array}{l}\text { Hino do país - } \\
\text { instrumental e letra }\end{array}$ & $\begin{array}{l}\text { Trabalho em equipe, comunicação, } \\
\text { criatividade }\end{array}$ & $\begin{array}{l}\text { Pode utilizar uma melodia já existente ou construir uma. } \\
\text { TDIC: app Remixlive e Beat snap. }\end{array}$ \\
\hline $\begin{array}{l}\text { Eleição do(a) } \\
\text { presidente }\end{array}$ & $\begin{array}{l}\text { Trabalho em equipe, argumentação, } \\
\text { tomada de decisões, gerenciamento } \\
\text { de informações }\end{array}$ & Indicar um presidente para a sua nação. \\
\hline $\begin{array}{l}\text { Criar site com a } \\
\text { identidade do país }\end{array}$ & $\begin{array}{l}\text { Criatividade, trabalho em equipe, } \\
\text { tomada de decisões, gerenciamento } \\
\text { de informações }\end{array}$ & $\begin{array}{l}\text { Criar um site apresentando o país, os serviços oferecidos } \\
\text { aos cidadãos, localização, pontos turísticos, moeda local, } \\
\text { economia, educação, idioma da nação. TDIC: Google } \\
\text { Sites. }\end{array}$ \\
\hline
\end{tabular}

Fonte: Elaborado pelos autores, 2019.

As atividades gamificadas são aquelas que têm como objetivo desenvolver habilidades sociais e competências como trabalho em equipe, argumentação, tomada de decisão, criatividade, gerenciamento de informações e comunicação entre os participantes. Essas 
Revista de Educação, Ciência e Tecnologia

habilidades foram identificadas em documentos que regulamentam a educação básica (BRASIL, 2013; 2017). O Quadro 2 apresenta um resumo das atividades gamificadas que foram planejadas para o 'This Land Is Mine!'.

Quadro 2 - Resumo das atividades gamificadas do 'This Land Is Mine!'

\begin{tabular}{|l|l|l|}
\hline \multicolumn{1}{|c|}{$\begin{array}{c}\text { Atividade e Tempo } \\
\text { Destinado }\end{array}$} & Objetivo & TDIC \\
\hline $\begin{array}{l}\text { A História } \\
15 \text { min. }\end{array}$ & $\begin{array}{l}\text { Desafiar os participantes para juntos criem uma tirinha com a } \\
\text { temática pré-estabelecida como 'Lenda Urbana'. }\end{array}$ & $\begin{array}{c}\text { Site } \\
\text { MakeBeliefsComix }\end{array}$ \\
\hline $\begin{array}{l}\text { O Resgate } \\
10 \text { min. }\end{array}$ & $\begin{array}{l}\text { Incentivar os participantes a relembrarem os conhecimentos em } \\
\text { questões como geografia e geolocalização. }\end{array}$ & $\begin{array}{c}\text { site Coordenadas } \\
\text { Geográficas }\end{array}$ \\
\hline $\begin{array}{l}\text { Disputa Diplomática } \\
5 \text { min. }\end{array}$ & Realizar duelo entre os presidentes e responder a um quiz. & Site Kahoot \\
\hline $\begin{array}{l}\text { MarshmallowChallenge } \\
18 \text { min. }\end{array}$ & $\begin{array}{l}\text { Desafiar os participantes a construírem a torre mais alta que fosse } \\
\text { possível com os seguintes materiais: } 20 \text { palitos de espaguete, } 1 \\
\text { metro de fita crepe, } 1 \text { metro de barbante e } 1 \text { marshmallow. }\end{array}$ & App Draw.io \\
\hline $\begin{array}{l}\text { Guerra } \\
5 \text { min. }\end{array}$ & $\begin{array}{l}\text { Desvendar um caça-palavras com a temática relacionada e com os } \\
\text { conteúdos abordados em sala de aula. }\end{array}$ & Site Geniol \\
\hline $\begin{array}{l}\text { Charada } \\
2 \text { min. }\end{array}$ & $\begin{array}{l}\text { Desvendar o problema apresentado usando pensamento rápido. } \\
\text { Usadas conforme o andamento da atividade. }\end{array}$ & $\begin{array}{l}\text { Usar de pensamento rápido para desvendar o nome da música } \\
\text { apresentada. Usadas conforme o andamento da atividade. }\end{array}$ \\
\hline $\begin{array}{l}\text { Música de Guerrilha } \\
2 \text { min. }\end{array}$ & \begin{tabular}{l} 
- \\
\hline
\end{tabular}
\end{tabular}

Fonte: Elaborado pelos autores, 2019.

\subsection{Aplicação e Avaliação}

A aplicação do 'This Land Is Mine!' ocorreu em um laboratório diferenciado, ao longo de quatro períodos de aula. Durante a aplicação, coube aos participantes explorar as diferentes TDIC sugeridas e experienciar como a gamificação pôde favorecer o engajamento. Nesse momento, os pesquisadores observaram o ambiente, tentando interferir minimamente e incentivando a realização das atividades de forma colaborativa. Cabe reiterar que ela foi aplicada com 12 participantes do IFRS, vinculados ao MPIE, que tem entre seus propósitos a formação de docentes.

Para realizar a avaliação da atividade, pontos fortes e aspectos que deveriam ser aprimorados, os participantes responderam a um questionário. Esse instrumento foi o mesmo usado para a coleta de dados. Ele foi estruturado com perguntas abertas e fechadas. As perguntas abertas foram importantes, porque permitiram capturar as percepções dos participantes sobre a abordagem usada em sala de aula; e as perguntas fechadas possibilitaram estabelecer parâmetros de comparação entre as respostas fornecidas por cada participante. Ao se concluir a coleta de dados, procedeu-se à sua análise, compondo-se o corpo dos resultados e as discussões deste trabalho.

\section{4 'This Land Is Mine!': Compreendendo as Dinâmicas, Mecânicas e Componentes}

O 'This Land Is Mine!' foi inspirado no jogo WAR, onde todas as ações são disputadas em um mapa mundial dividido em seis regiões (Europa, Ásia, África, América do Norte, 
América do Sul e Oceania); e no Monopoly, sendo ambos jogos de tabuleiro baseados em conquistas de territórios e bens. Esses jogos ainda utilizam cartas com missões e objetivos que devem ser atingidos pelos jogadores. De forma semelhante, a presente estratégia fundamentase no uso de cartas-objetivo, de modo que é necessário completar uma missão de acordo com a carta sorteada, e quem concluir o objetivo torna-se o vencedor da atividade gamificada.

Visando a motivar os participantes e adicionar um fator de storytelling à gamificação, resolveu-se criar uma identidade visual (Figura 2) (SILVA; OLIVEIRA; MARTINS, 2017). Para promover maior dinamismo no design, foram utilizadas cores complementares (azul e laranja) que despertam o movimento, a inquietação, e estimulam o pensamento e o intelecto (FARINA; PEREZ; BASTOS, 2011). Para realizar as atividades gamificadas, foram criadas cartas, cada uma com características gráficas próprias, com uma ilustração que remete à finalidade do objetivo a ser atingido. A ideia era demonstrar aos participantes como associar elementos visuais a uma estratégia gamificada e incentivá-los a adotar abordagens semelhantes nas suas práticas pedagógicas.

Figura 2 - Cartas do jogo This Land Is Mine!

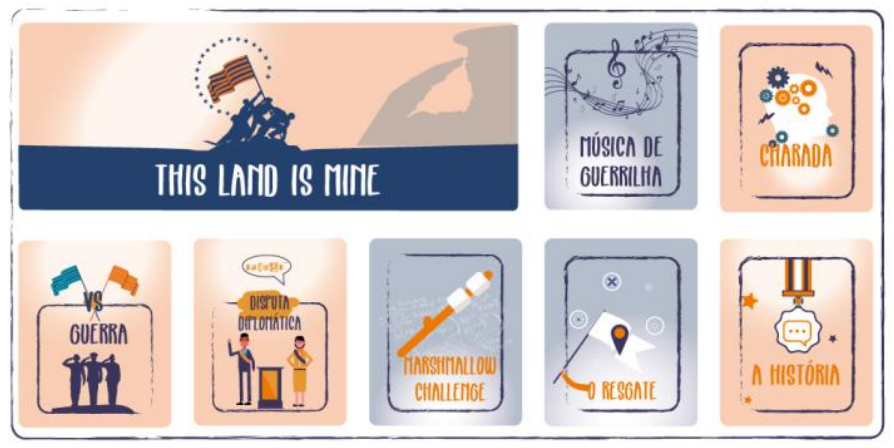

Fonte: Elaborado pelos autores, 2019.

As cartas poderiam ser escolhidas de forma aleatória. Todas elas serão apresentadas detalhadamente nas subseções a seguir.

\subsection{Carta - A História}

A carta 'A História' teve como objetivo desafiar os jogadores a criarem uma tira com a temática pré-estabelecida como 'Lenda Urbana' de seu país. As equipes tiveram total liberdade para escolher a história que queriam representar gráfica e textualmente na ferramenta disponibilizada Make Beliefs Comix, escolhida para esse fim (Figura 3). Essa estratégia gamificada empregou a dinâmica da narrativa; utiliza as mecânicas de feedback, desafio, cooperação e competição, e recompensa; bem como os componentes de missões, pontuação, combate e conquista. O propósito dessa missão consistia em explorar, no eixo da leitura e da escrita, outros tipos de produções textuais; "compreende as práticas de produção de textos verbais, verbo-visuais e multimodais, de diferentes gêneros textuais, considerando a situação comunicativa, os objetivos visados e os destinatários do texto" (BRASIL, 2017, p. 64). Com essa missão, foi possível explorar, por exemplo, as dimensões da política, da cultura e da economia, comparando o país criado a outros países do mundo. Isso possibilitou explorar diversas unidades temáticas no contexto da disciplina de Geografia. 
Figura 3 - Atividade 'A História'

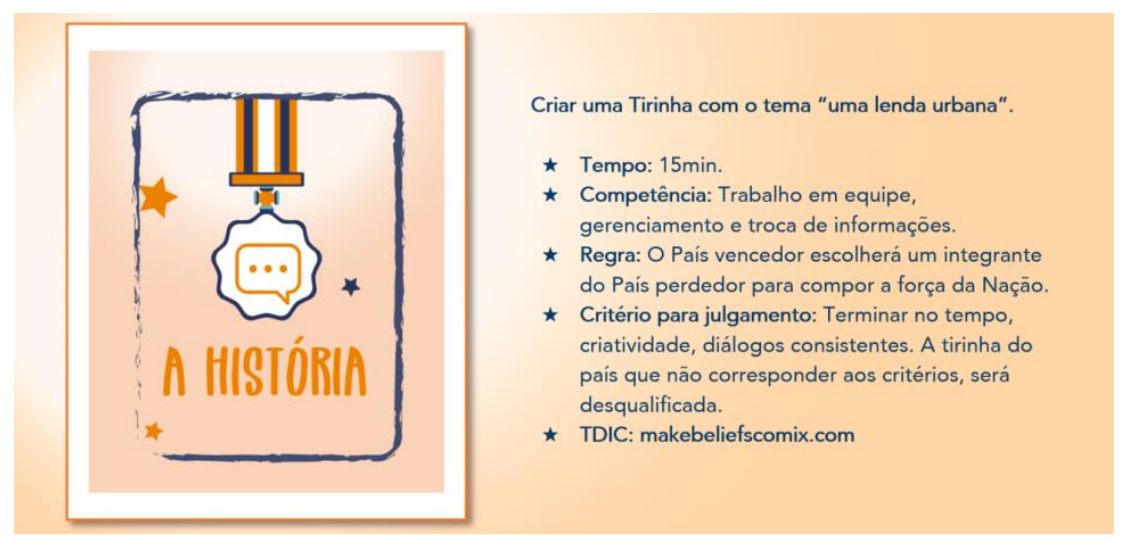

Fonte: Elaborado pelos autores, 2019.

Além disso, a atividade visou a trabalhar as competências: trabalho em equipe, gerenciamento e troca de informações. A equipe que finalizasse a tarefa de acordo com os critérios de julgamento pontuaria no placar geral.

\subsection{Carta - O Resgate}

$\mathrm{Na}$ missão 'O Resgate' (Figura 4), cinco participantes de uma equipe precisavam ser resgatados em diferentes pontos da cidade. Para isso, foram fornecidos cinco códigos (latitude $\mathrm{x}$ longitude) dos pontos onde os soldados supostamente estavam abrigados e esperando pelo socorro. Para descobrir a localização correta e enviar o resgate, os participantes precisavam acessar o site Coordenadas Geográficas, digitar os códigos e assim desvendar as localizações. O tempo máximo para realização da tarefa foi de 10 minutos, e ela teve cinco rodadas (uma para cada código). Para cada rodada, o código foi compartilhado com todos (usando um telão); e, ao emitir um sinal, as equipes iniciaram a pesquisa. Para responder, um integrante da equipe teve de sinalizar a conclusão da busca.

A intenção inicial dessa abordagem consistiu em explorar o sistema de coordenadas geográficas, previsto na BNCC na disciplina de Geografia, viabilizando explorar o raciocínio geográfico, que permite identificar a "Posição particular de um objeto na superfície terrestre. A localização pode ser absoluta (definida por um sistema de coordenadas geográficas) ou relativa (expressa por meio de relações espaciais topológicas ou por interações espaciais)." (BRASIL, 2017, p. 312). Porém, com a aplicação dessa missão em sala de aula, percebeu-se que a temática envolvida poderia ser utilizada para desenvolver conhecimentos vinculados ao plano cartesiano - "coordenadas cartesianas $\left(1^{\circ}\right.$ quadrante) e representação de deslocamentos no plano cartesiano" -, habilidade prevista na BNCC (BRASIL, 2017, p. 252). 
Figura 4 - Atividade 'O Resgate'

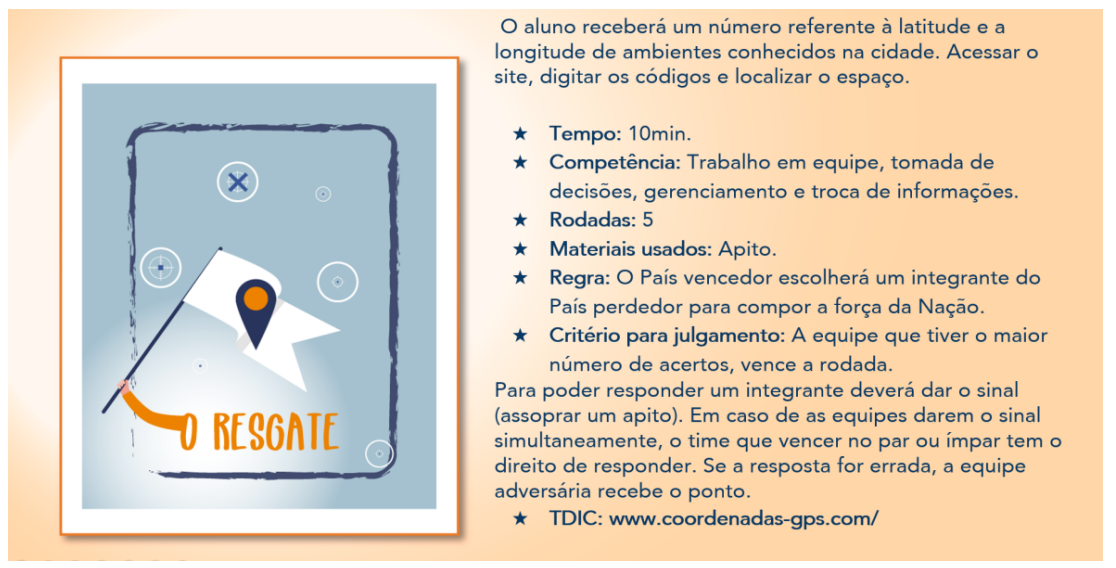

Fonte: Elaborado pelos autores, 2019.

Nessa atividade, foram aplicadas as seguintes competências: trabalho em equipe, tomada de decisões e gerenciamento e troca de informações. A dinâmica aplicada foi a narrativa; as mecânicas adotadas foram feedback, desafio, cooperação e competição, e recompensa; e os componentes usados foram missões, pontuação, combate e conquista.

\subsection{Carta - Disputa Diplomática}

Para estimular as competências de comunicação e de tomadas de decisão, assim como criar um momento de duelo entre os integrantes da equipe, a narrativa da 'Disputa Diplomática' apresentou uma situação onde um impasse político só poderia ser resolvido pelos presidentes eleitos das nações criadas, respondendo a perguntas no formato de quiz. A TDIC utilizada para essa atividade foi a ferramenta Kahoot, cujo tema relacionou-se à gamificação. Os participantes precisaram responder a seis perguntas de múltipla escolha, conforme conhecimento prévio. Após a aplicação do quiz, os pesquisadores fizeram uma breve explanação sobre as temáticas abordadas nas questões, a fim de embasar os conceitos abordados.

No caso dessa atividade gamificada, foram empregados os seguintes elementos da gamificação: narrativa como dinâmica; nas mecânicas, desafio, competição e recompensa; e, como componentes, missões, pontuação, combate e conquista.

Figura 5 - Atividade 'Disputa Diplomática'

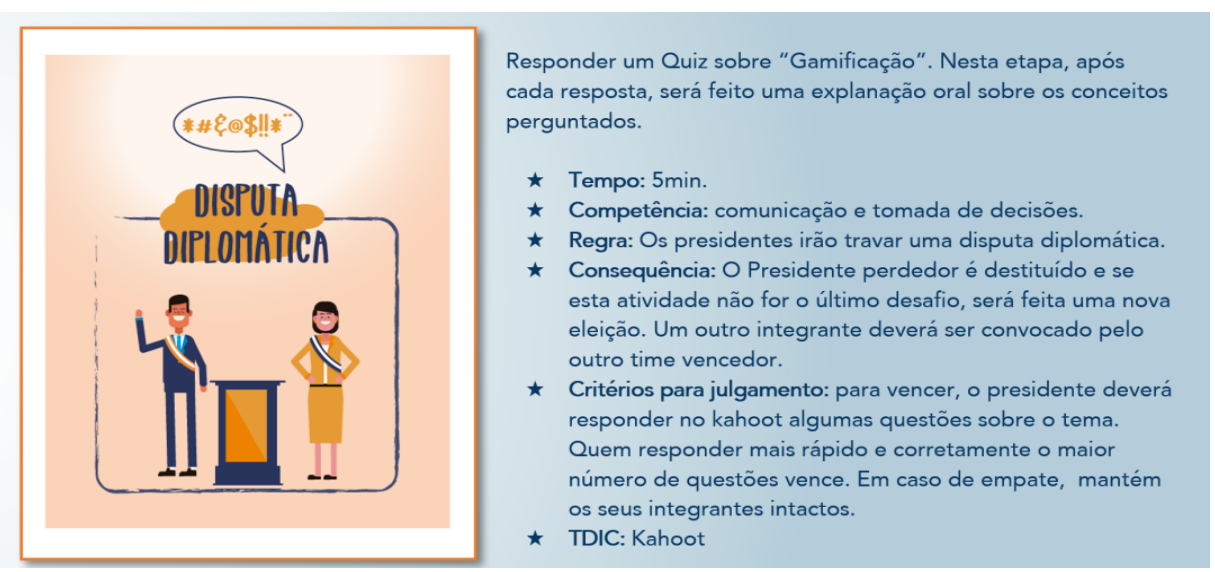

Fonte: Elaborado pelos autores, 2019. 
Considerando essa missão, optou-se por demonstrar aos docentes que a gamificação pode ser utilizada para:

Exercitar a empatia, o diálogo, a resolução de conflitos e a cooperação, fazendo-se respeitar e promovendo o respeito ao outro, com acolhimento e valorização da diversidade de indivíduos e de grupos sociais, seus saberes, identidades, culturas e potencialidades, sem preconceitos [...] reconhecendo-se como parte de uma coletividade com a qual deve se comprometer. (BRASIL, 2017, p. 19).

Conforme estabelece a competência geral número nove da BNCC.

\subsection{Carta - MarshmallowChallenge}

A atividade 'MarshmallowChallenge' (Figura 6) é consolidada em diversos ambientes de trabalho e aprendizado no mundo todo. Para este jogo, sua aplicação teve como finalidade estimular nos jogadores as competências: trabalho em equipe, tomada de decisões, gerenciamento e troca de informações. As equipes tiveram o desafio de construir a torre mais alta que conseguissem, utilizando 20 palitos de espaguete, um metro de fita crepe e um metro de barbante. Ao final da construção, a edificação deveria manter todo o seu peso e também o peso de um marshmallow. Como critério para julgamento, com uma fita métrica, as torres construídas foram medidas pelos pesquisadores e a que atendeu a todos os critérios prévios pontuou no placar. Para ganhar um ponto extra, foi adicionada à atividade original uma tarefa de documentar todo o processo de construção usando uma ferramenta de workflow Draw.io, da Google.

Essa missão possibilitou demonstrar aos participantes como diversos temas e habilidades podem ser integrados em uma única atividade gamificada. A relação imediata realizada foi com a matemática "Grandezas e medidas". Porém, foram identificadas outras relações com conteúdos do ensino fundamental, tais como: (i) noções de geometria, através da construção de figuras planas; (ii) relações com o meio ambiente e a produção de resíduos, visto que, na aplicação, alguns participantes identificaram que o material usado na atividade seria descartado, podendo ser abordadas temáticas como consumo consciente, reciclagem, reuso, entre outros; (iii) construção do conhecimento em Arte, visando a desenvolver o "fazer artístico, quando os sujeitos criam, produzem e constroem", e o transformando em um "processo permeado por tomadas de decisão, entraves, desafios, conflitos, negociações e inquietações" (BRASIL, 2017, p. 152).

Além dessas relações, durante a avaliação, foi possível perceber que, no contexto da educação infantil, essa atividade gamificada possibilitou explorar, de forma prática, alguns dos direitos das crianças nesse nível educacional, tais como: o brincar, explorando materiais e espaços diferenciados e vivenciando diferentes experiências sensoriais, através dos diversos materiais; o explorar de novas formas e texturas; e o expressar de sua criatividade, dúvidas e opiniões. 
Figura 6 - Atividade 'MarshmallowChallenge'

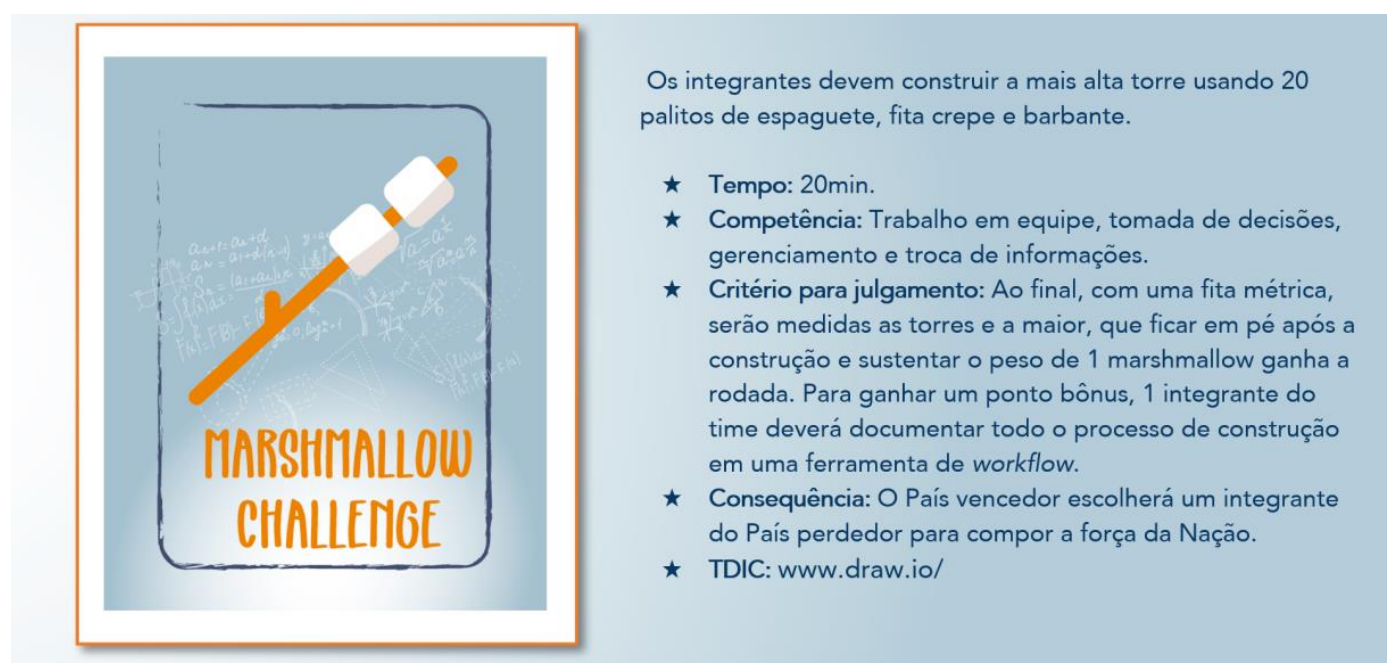

Fonte: Elaborado pelos autores, 2019.

Essa atividade gamificada adotou as mecânicas de feedback, desafio, cooperação e competição, e recompensa; e os componentes utilizados compreenderam missões, pontuação, combate e conquista.

\subsection{Carta - Guerra}

A atividade 'Guerra' (descrita em síntese na Figura 7) teve como finalidade desvendar um caça-palavras com a temática relacionada aos conteúdos abordados em sala de aula. A atividade exigiu as competências: trabalho em equipe, tomada de decisões, gerenciamento e troca de informações, a fim de encontrar o maior número de palavras no pequeno espaço de tempo. Para cumprir essa missão, o presidente da nação indicou três integrantes para o combate. Em caso de derrota, o país perdedor entregaria toda a sua equipe ao país vencedor. A equipe que encontrou o maior número de palavras no menor tempo venceu a rodada. A ferramenta utilizada para elaborar o caça-palavras foi o Geniol, que, além de permitir que sejam produzidos novos jogos com a temática desejada, ainda disponibilizou aos seus usuários, em seu site, jogos desafiadores e passatempos com diversos níveis de dificuldade.

O objetivo dessa atividade era fortalecer, junto aos participantes, a ideia de colaboração, pois a resolução deveria ocorrer através de interações entre os indivíduos da equipe, caracterizando a formação da Zona de Desenvolvimento Proximal (ZDP) proposta por Vygotsky (1998), a qual pode ser definida como a distância entre conhecimento real de um indivíduo e o que consegue solucionar de forma individual; e o conhecimento potencial, que corresponde ao que ele atinge com a intervenção dos colegas ou do professor. Desse modo, atividades realizadas em equipe (baseadas em interações reais) podem favorecer uma maior aquisição do conhecimento (VYGOTSKY, 1998). 
Figura 7 - Atividade 'Guerra'

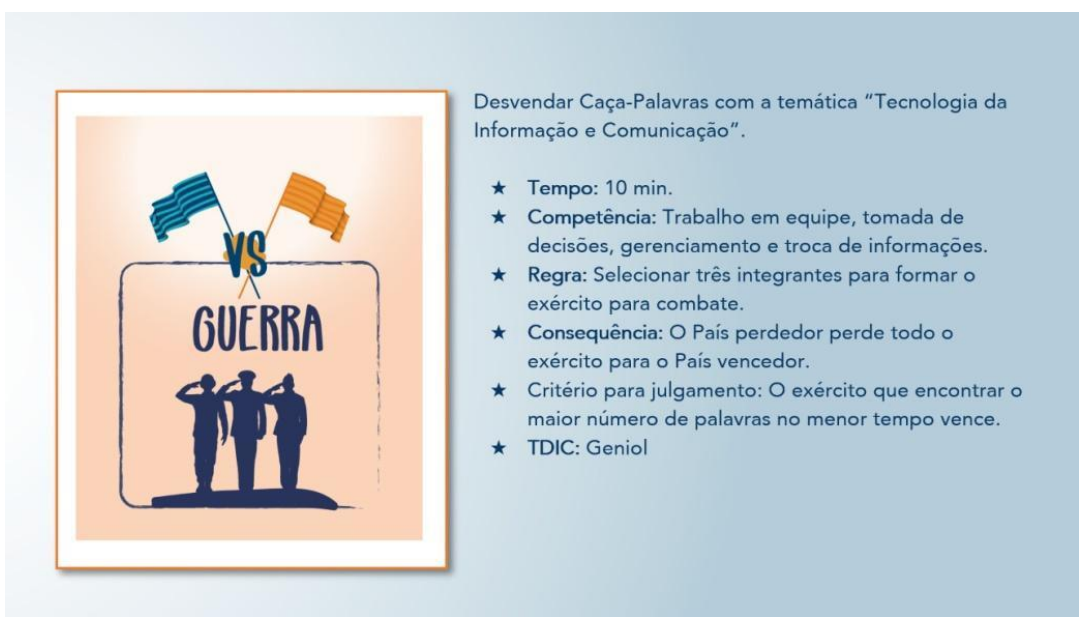

Fonte: Elaborado pelos autores, 2019

Os elementos aplicados nessa atividade foram: narrativa como dinâmica; nas mecânicas, desafio, competição e recompensa; e os componentes utilizados foram missões, pontuação, combate e conquista.

\subsection{As Cartas Coringas}

Além das missões, foram propostas as cartas coringas, as quais puderam substituir qualquer outra do baralho, caracterizando-se, portanto, pela sua neutralidade. $\mathrm{Na}$ 'This Land Is Mine!', uma atividade coringa objetivou a quebra do ritmo do jogo e instigou os participantes ao pensamento rápido, trazendo de memória suas vivências e experiências para resolver o problema apresentado. Por exemplo, na carta 'Qual é a música?', era exibido um trecho da letra de uma música, e as equipes precisaram identificar o cantor/grupo musical ou nome da música.

As atividades coringas exploraram diversos assuntos no formato de charadas, elementos musicais, problemas de lógica, entre outras questões que fizeram os participantes, em equipe, desvendar enigmas. Em 'This Land Is Mine!', foram estimadas seis cartas coringas que, assim como as cartas das atividades gamificadas, foram escolhidas pelo presidente da nação. Para essa experiência gamificada, foram criados dois tipos: Charada e Música de Guerrilha, esquematizados na Figura 8. Com essas duas cartas, o objetivo era reforçar, junto aos professores, que uma atividade gamificada poderia ser usada para desenvolver o raciocínio lógico, bem como para fortalecer uma identidade relacionada com a cultura musical dos seus estudantes - ambas as habilidades são reconhecidas como importantes no contexto da BNCC (BRASIL, 2017).

Figura 8 - Atividade Coringa

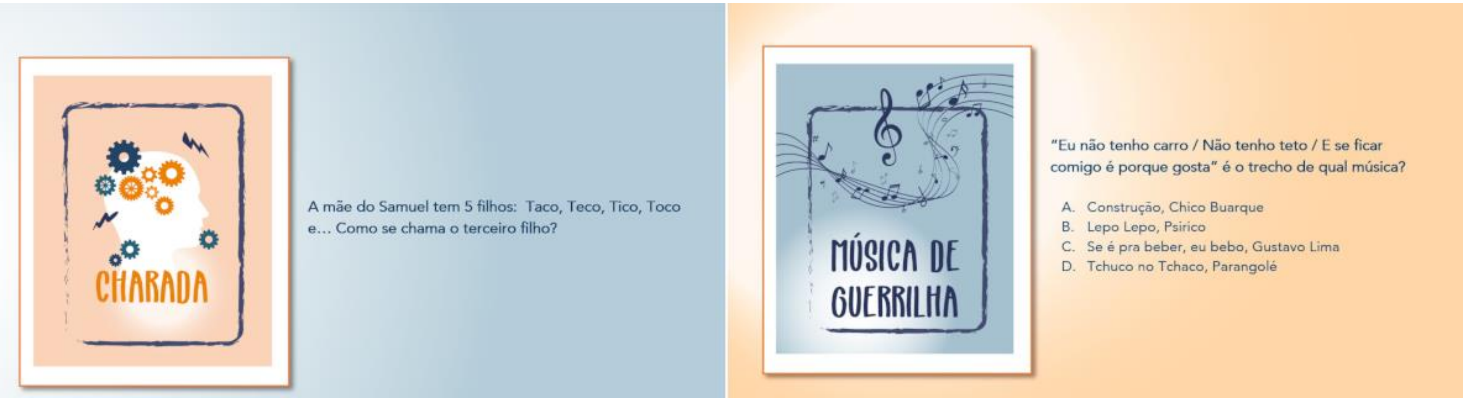

Fonte: Elaborado pelos autores, 2019. 
Os elementos explorados na atividade coringa foram: feedback, desafio, cooperação e competição, e recompensa, referentes à mecânica. E os componentes utilizados foram missões, pontuação, combate e conquista.

\section{5 'This Land Is Mine!': Regras do Jogo}

A dinâmica da estratégia This Land Is Mine!' é dividida em duas partes: atividades criativas (Quadro 1), que não pontuam, seguidas das atividades gamificadas (Quadro 2), que pontuam para as equipes participantes. Ela inicia com a divisão igualitária em duas ou mais equipes, compostas por cinco a nove integrantes. Cada participante tem a liberdade de escolher a qual equipe deseja pertencer.

A divisão do grande grupo em equipes proporciona a composição de dois ou mais países (nações), sendo possível identificá-los por cores. A primeira tarefa proposta é formar a identidade do país através de atividades criativas listadas no Quadro 1. Essa primeira parte da dinâmica, chamada de pré-jogo, tem como objetivo explorar a criatividade dos participantes através de atividades manuais/criativas e intelectuais. Além disso, os integrantes também devem eleger um presidente (representante maior da nação), que será o líder do grupo, responsável por diversas ações dentro da equipe, como: escolher a carta da rodada; "confiscar" pessoalmente o integrante da equipe adversária perdedora da batalha; participar da atividade diplomática; e gerenciar as tarefas dentro do grupo, como, por exemplo, determinar os integrantes que deverão compor a equipe que fará parte da atividade 'Guerra'.

Na segunda parte da dinâmica, chamada de atividades gamificadas (Quadro 2), todas as cartas são distribuídas viradas sobre uma mesa. O presidente da nação, alternadamente, tem a responsabilidade de escolher, ao acaso, uma carta para ser executada. Antes de iniciar a escolha das cartas, os dois presidentes jogam o par e ímpar para estabelecer quem iniciará o jogo. A carta escolhida é exibida aos participantes (por exemplo, usando um computador ou um projetor), onde são lidas as regras da atividade, qual TDIC deve ser utilizada, e o tempo de sua condução. Quando uma carta de atividade gamificada é escolhida, ela não pode mais ser usada, com exceção das cartas coringas. Isso foi planejado assim para que a aplicação da estratégia gamificada viabilizasse o desenvolvimento de todas as habilidades previstas pelas atividades sistematizadas.

As atividades gamificadas são cronometradas e, sendo as missões desempenhadas corretamente, pontua a equipe que cumprir a tarefa no menor tempo. A princípio, somente uma equipe pontua por rodada, mas, na persistência do empate, após a análise dos critérios estabelecidos na atividade e a análise do uso correto da ferramenta proposta pelos pesquisadores, os integrantes são mantidos em suas equipes, e ambos os times pontuam. No entanto, se somente uma equipe for vencedora da rodada, a regra é: a equipe que pontuar escolhe um integrante da outra para fazer parte de sua nação (conquista). Para recuperar o integrante perdido, ou escolher um outro integrante para sua equipe, o país perdedor deverá ganhar a próxima rodada (combate e competição), correndo o risco de recuperar o participante ou perder outro. O país vencedor em 'This Land Is Mine!' será a equipe que obtiver a maior pontuação ao final de todas as rodadas. A pontuação é apresentada visualmente em um placar geral atualizado ao final de cada atividade.

A Figura 9 ilustra os participantes realizando a atividade Gamificada 'A História', onde cada uma das nações utilizou os elementos visuais e gráficos relativos à identidade de seu país, o qual já havia sido caracterizado na etapa criativa. 
Figura 9 - Jogadores montando a história em quadrinhos

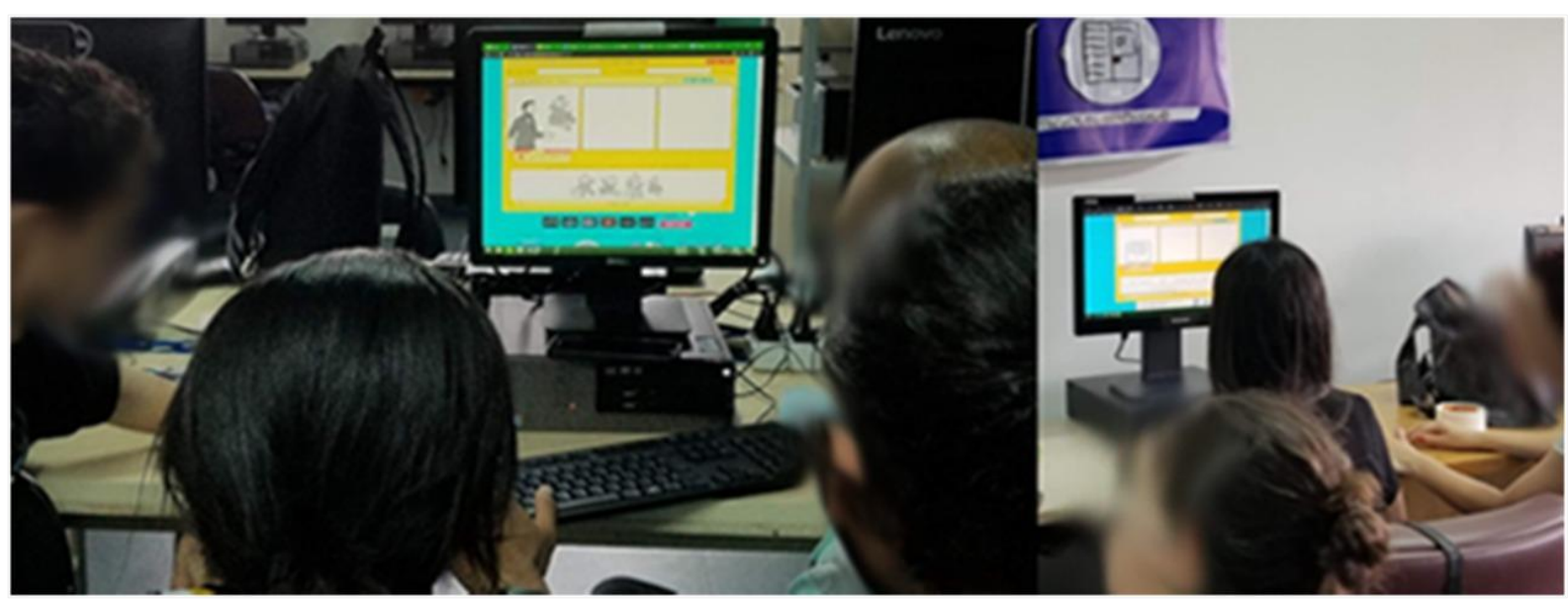

Fonte: Elaborado pelos autores, 2019.

$\mathrm{Na}$ atividade 'MarshmallowChallenge', geralmente, as equipes tendiam a se dividir para conseguir finalizar a missão no tempo previsto, visto que existiam duas tarefas inclusas em uma, sendo a construção da torre e sua documentação na ferramenta definida para a atividade. A Figura 10 ilustra que foi exatamente isso que ocorreu: enquanto parte da equipe tentava montar a torre, a outra parte dedicou-se à documentação do processo de montagem.

Figura 10 - Jogadores executando a atividade 'MarshmallowChallenge'.

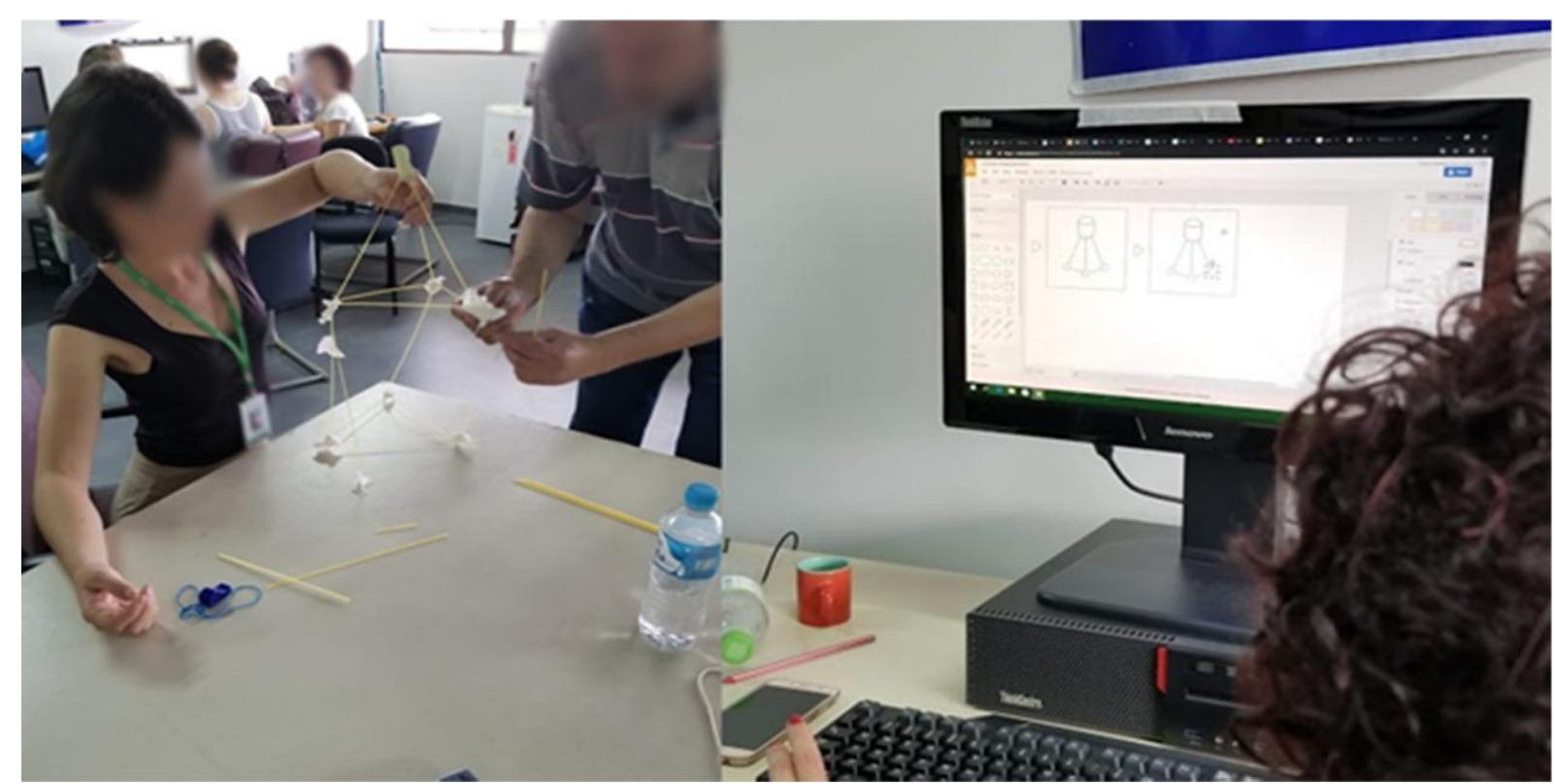

Fonte: Elaborado pelos autores, 2019.

Nessa etapa da aplicação, através da observação dos pesquisadores, foi possível identificar que algumas atividades gamificadas haviam sido planejadas para explorar determinada habilidade prevista na BNCC, mas, ao longo de seu andamento, outras possibilidades e habilidades eram propostas e identificadas pelos participantes.

\section{Resultados e discussões}

A avaliação da estratégia foi realizada em dois momentos: a reflexão em conjunto e um questionário de avaliação com sete questões, sendo cinco perguntas abertas e duas fechadas. Durante a reflexão, os estudantes relataram que, como docentes, antes de participar, não se sentiam preparados para aplicar gamificação em aula, pois achavam o conceito 
complicado e com muitos componentes, isso porque acreditavam que todos os elementos eram obrigatórios. Filho, Silva e Inocêncio (2018) argumentam que existe "a falta de uma base sólida do que é uma prática pedagógica gamificada"; e Fardo (2013) declara que o uso de Gamificação no contexto escolar exige boa "compreensão por parte dos professores".

Ao serem questionados sobre o fator competição do jogo, muitos relataram que o comportamento competitivo não atrapalhou a atividade, mas ficou visível que existia o sentimento de competição bem elevado, mesmo se desenvolvendo as atividades com participantes adultos e professores. Para Busarello (2016), a competição torna-se um aspecto negativo no contexto educacional quando prejudica um participante do jogo, ou quando reduz as possibilidades de aprendizagem. Alguns relataram que o tempo foi reduzido para desenvolver as atividades gamificadas - especificamente para as atividades criativas, parte do grupo afirmou que seria necessário estimar um pouco mais de tempo. Logo, percebe-se que, ao planejar atividades gamificadas, seria ideal realizar testes antes da aplicação, visando a estimar o tempo de forma mais precisa.

Quando questionados sobre as atividades de que mais gostaram, uma informação chamou a atenção dos pesquisadores (Gráfico 1): a MarshmallowChallenge, com 30\%, foi a atividade que mais agradou os participantes, apesar de o trabalho ser totalmente manual; seguido das atividades criativas (26\%), que também não usam TDIC na sua execução. Desse modo, conclui-se que as atividades manuais foram consideradas mais prazerosas do que as digitais. Acredita-se que isso pode ter ocorrido porque a maioria das TDIC usadas não eram dominadas pelos participantes e, ainda, que as atividades envolvendo algum tipo de competição não estavam adequadas ao perfil dos pesquisados.

Gráfico 1 - Preferências com relação aos elementos da estratégia This Land Is Mine!

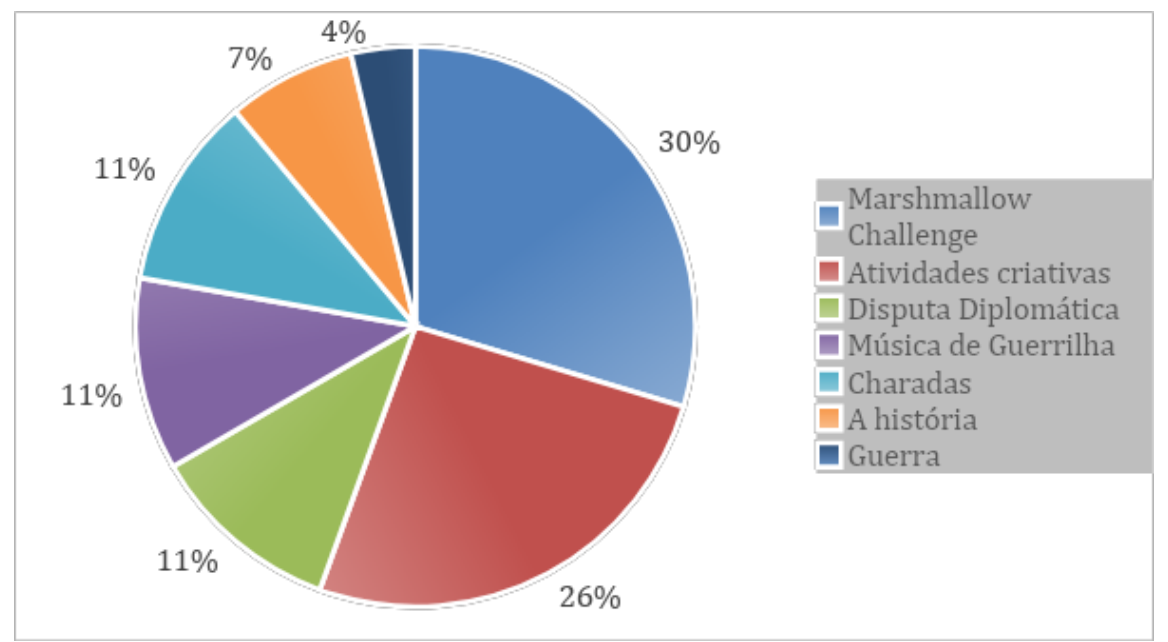

Fonte: Elaborado pelos autores, 2019.

Quando questionados " $\mathrm{Na}$ sua opinião, o jogo gamificado estimulou, de maneira adequada, a cooperação entre integrantes?", todos foram unânimes em declarar que a estratégia incentivou o trabalho em equipe. Quando perguntados sobre as TDIC, pôde-se perceber que a plataforma Kahoot, o Google Sites (criação de sites), o Makebeliefscomix (histórias em quadrinhos) e o Draw.io (elaboração de diagramas) foram as mais relacionadas na lista de preferências dos participantes. Nos relatos posteriores, os jogadores justificaram que o Kahoot foi o mais citado como o recurso que eles mais usariam em sala de aula, pela facilidade de uso, por poder jogar no computador e no celular, e porque a linguagem é adequada e mais próxima da realidade dos seus alunos (Gráfico 2). Quanto ao Google Sites, muitos afirmaram que não sabiam que era "fácil" criar um site e, por isso, gostaram de aprender e interagir com essa tecnologia. 
Gráfico 2 - Preferência das TDICs que usariam em sala de aula

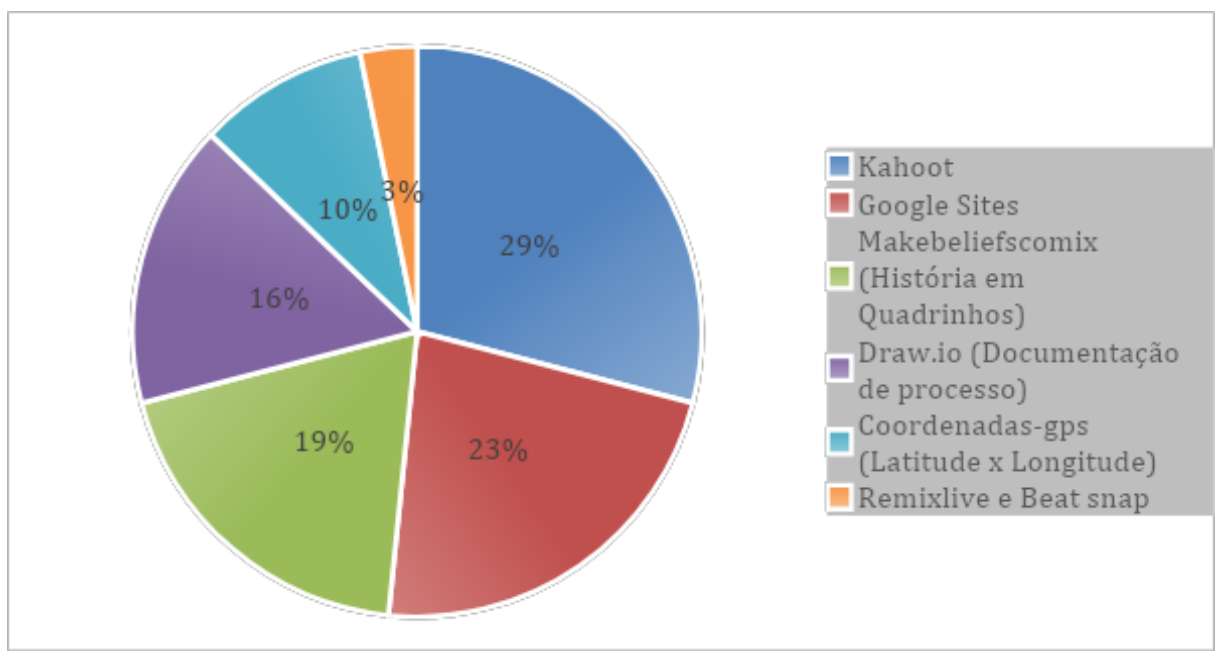

Fonte: Elaborado pelos autores, 2019.

Ao serem questionados "Você conseguiu reconhecer as técnicas de gamificação no jogo? Comente sua resposta", a grande maioria dos participantes afirmou que sim. Entretanto, um relato chamou a atenção dos pesquisadores: "Acho que precisaria ter sido abordado no fechamento quais as técnicas de gamificação, pois não fica claro pra mim, se todas foram utilizadas, por exemplo." Ou seja, percebe-se que faltou, ao término da dinâmica, realizar um fechamento correlacionando os elementos da gamificação e o contexto onde cada um deles foi empregado, visando a esclarecer ainda mais como essa técnica pode ser usada em sala de aula.

Um outro questionamento feito ao grupo foi "Qual(is) sentimento(s) quando um colega era retirado da equipe, após perder uma batalha? Comente sua resposta". A maioria dos alunos relatou um sentimento de perda e tristeza, e sempre que podiam tentavam resgatálo, como mostram alguns comentários dos alunos: "Sentimento de perda e desfalque, pois o colega contribuía com uma inteligência e habilidades que, basicamente, ele apenas possuía no grupo, ou de maneira mais acentuada. Sempre que foi oportunizado, os grupos resgataram os membros perdidos ao invés de buscar raptar um outro membro da outra equipe, pois esse membro possuía uma inteligência que estava defasada no grupo."; "Ficávamos chateados, uma vez que a equipe também 'perdia' forças para as próximas tarefas."; "Desestabilização da equipe, era necessário repensar os novos pontos fortes e fracos do restante do grupo." Esses comentários deixam claro que, quando a gamificação é desenvolvida em equipe, a relação de pertencimento a um grupo é potencializada. Além disso, os participantes compreenderam que, quando um trabalho é realizado colaborativamente, as equipes devem ser estruturadas com alunos de perfil diferenciado.

Em 'This Land is Mine!', a equipe precisa estar estimulada, envolvida, atenta e integrada para atingir os resultados, que incluem ganhar a rodada e capturar um integrante do outro país, assim aumentando o número de habilidades dentro de sua nação. Cada rodada possui suas regras particulares que precisam ser respeitadas e seguidas, a fim de manter a ordem da atividade e atingir o objetivo de aprendizagem proposto.

\section{Considerações Finais}

Para que a aplicação da gamificação em sala de aula ocorra com sucesso, seus elementos devem ser escolhidos com cuidado, implementados em processos que tenham alguma intencionalidade pedagógica, ou seja, o uso deve estar vinculado a algum conteúdo significativo para o estudante, e as dinâmicas devem permitir habilidades necessárias para o 
século XXI. As dinâmicas e mecânicas da gamificação podem favorecer o engajamento e a motivação, mas, para que isso ocorra, a sua aplicação deve ser planejada e organizada.

Durante o planejamento da estratégia gamificada aqui relatada, houve a preocupação em promover o uso e a experimentação de ferramentas de TDIC durante as atividades, de modo a deixar a dinâmica mais interessante e emocionante, além de favorecer a apropriação delas pelos participantes que ainda não as conheciam. Quanto às recompensas do jogo, que é considerado um benefício concedido ao jogador por alguma ação ou conquista, é possível usar chocolate, objetos construídos durante a prática, entre outros recursos. No caso deste trabalho, foram distribuídos bombons a todos os participantes que se envolveram na prática gamificada, como forma de valorizar a participação, independentemente da classificação de cada equipe, visto que, ao término da atividade, restou apenas um país composto por todos os 12 participantes. Apesar de apenas um grupo ser o vencedor em função da pontuação, a ideia principal é de que todos o sejam. Afinal, não existe conquista sem colaboração, e não há jogo sem participação.

Por fim, é importante destacar que, no planejamento da atividade gamificada, devem ser previstas opções de atividades plugadas e desplugadas (BELL, 2009), dando opções de jogabilidade para diferentes públicos, para que a ação possa ser realizada em escolas que possuem poucos recursos tecnológicos, por exemplo.

\section{Referências}

ALVES, F. Gamification: como criar experiências de aprendizagem engajadoras. Um guia completo: do conceito à prática. 2. ed. São Paulo: DVS, 2014.

ARRUDA, J. S. et al. A. Tecnologias digitais e a prática docente: como as metodologias ativas podem transformar a formação de professores. In: Workshop de Informática na Escola, Brasília, 2019. Anais (...). Brasília: Sociedade Brasileira de Computação, 2019, p. 142-143. Disponível em: https://www.br-ie.org/pub/index.php/wie/article/view/8682/6243. Acesso em: 06 maio, 2020.

BACICH, L.; MORAN, J. Metodologias ativas para uma educação inovadora: uma abordagem teórico-prática. Porto Alegre: Penso, 2018.

BAKKER, A. B.; ALBRECHT, S. L.; LEITER, M. P. Work engagement: further reflections on the state of play. European Journal of Work and Organizational Psychology, v. 20, n. 1, p. 74-88, 2011.

BASTOS, C. A. R.; SIQUEIRA, S. W. M. Uma iniciativa de formação docente em design instrucional sob os enfoques de design thinking e experiência do usuário. In: Workshop de Informática na Escola, Brasília, 2019. Anais (...). Brasília: Sociedade Brasileira de Computação, 2019, p. 869-878. Disponível em: https://www.brie.org/pub/index.php/wie/article/view/8587. Acesso em: 06 maio, 2020.

BELL, T. et al. Computer science unplugged: school students doing real computing without computers. The New Zealand Journal of Applied Computing and Information Technology, v. 13, n. 1, p. 20-29, 2009.

BRASIL. Diretrizes Curriculares Nacionais Gerais da Educação. Brasília: MEC/Secretaria de Educação Básica, 2013. 
BRASIL. Base Nacional Comum Curricular. Brasília: MEC/Secretaria de Educação Básica, 2017.

BRITO, E. S.; VIANA, F. R. O uso de metodologias ativas na formação docente de estudantes residentes do curso de Letras: língua portuguesa e Libras da UFRN. In: Congresso Brasileiro de Informática na Educação, Brasília, 2019. Anais (...). Brasília: Sociedade Brasileira de Computação, 2019, p. 711-719. Disponível em: https://www.brie.org/pub/index.php/wcbie/article/view/9020/6564. Acesso em: 06 maio, 2020.

BURKE, B. Gamify: how gamification motivates people to do extraordinary things. New York: Routledge, 2016.

BUSARELLO, R. I. Gamification: princípios e estratégias. São Paulo: Pimenta Cultural, 2016.

DECI, E. L.; RYAN, R. M. Intrinsic motivation and self-determination in human behavior. New York: Plenun, 1995.

FARDO, M. L. A Gamificação aplicada em Ambientes de Aprendizagem. RENOTE Revista Novas Tecnologias na Educação, v. 11, n. 1, p. 1-9. 2013.

FARINA, M.; PEREZ, C.; BASTOS, D. Psicodinâmica das cores em comunicação. São Paulo: Blucher, 2011.

FILIPPO, D.; ROQUE, G.; PEDROSA, S. Pesquisa-ação: possibilidades para a Informática Educativa. In: JAQUES, Patrícia Augustin; PIMENTEL, Mariano; SIQUEIRA; Sean; BITTENCOURT, I. (Org.) Metodologia de Pesquisa Científica em Informática na Educação: concepção de pesquisa. Porto Alegre: SBC, 2019. (Série Metodologia de Pesquisa em Informática na Educação, v.3). p. 1-29.

FILHO, R. G. S., SILVA, H. A., INOCÊNCIO, A. C. G. Um mapeamento sistemático sobre fatores que podem influenciar na eficiência da gamificação. In: Simpósio Brasileiro de Informática na Educação, Fortaleza, 2018. Anais (...). Fortaleza: Sociedade Brasileira de Computação, 2018. p. 506-514. Disponível em: https://www.brie.org/pub/index.php/sbie/article/view/8007/5701. Acesso em: 12 abr., 2019.

GIL, A. C. Métodos e técnicas de pesquisa social. 6. ed. São Paulo: Atlas, 2008.

GONÇALVES, L. L.; et al. Gamificação na Educação: um modelo conceitual de apoio ao planejamento em uma proposta pedagógica. In: Simpósio Brasileiro de Informática na Educação, Uberlândia, 2016. Anais (...). Uberlândia: Sociedade Brasileira de Computação, 2016. p. 1305-1310. Disponível em: http://www.brie.org/pub/index.php/sbie/article/view/6818/4703. Acesso em: 23 set., 2019.

HUIZINGA, J. Homo Ludens. 4. ed. São Paulo: Perspectiva, 2000.

KAPP, K. M. The gamification of learning and instruction: game-based methods and strategies for training and education. San Francisco: Pfeiffer, 2012.

KIM, S. et al. Gamification in learning and education: enjoy learning like gaming. Switzerland: Springer International Publishing; ePUB, 2018. 
KITCHENHAM, B. et al. Systematic literature reviews in software engineering: a systematic literature review. Information and software technology, v. 51, p. 7-15, jan., 2009. Disponível em: https://doi.org/10.1016/j.infsof.2008.09.009. Acesso em: 20 abr., 2019.

RESNICK, M.; ROBINSON, K. Lifelong kindergarten: cultivating creativity through projects, passion, peers, and play. Cambridge, Massachusetts: MIT Press, 2017.

MUZEKA, I.; MARQUARDT E. Gamificação e o desenvolvimento das inteligências múltiplas no Ensino Superior. Rev. FSA, Teresina, v. 14, n. 6, p. 109-124, nov./dez. 2017.

OGAWA, A.; KLOCK, A. C. T.; GASPARINI, I. Avaliação da gamificação na área educacional: um mapeamento sistemático. In: Simpósio Brasileiro de Informática na Educação, Uberlândia, 2016. Anais (...). Uberlândia: Sociedade Brasileira de Computação, 2016. p. 440-449. Disponível em: https://www.brie.org/pub/index.php/sbie/article/view/6725. Acesso em: 03 maio, 2019.

POYATOS NETO, H. R. Gamificação: engajando pessoas de maneira lúdica. São Paulo: Fiap, 2015; ePUB.

SILVA, J. A. L.; OLIVEIRA, F. C. S.; MARTINS, D. J. S. Storytelling e gamificação como estratégia de motivação no ensino de programação com Python e Minecraft. In: Simpósio Brasileiro de Jogos e Entretenimento Digital, Foz do Iguaçu, 2018. Anais (...). Foz do Iguaçu: Sociedade Brasileira de Computação, 2018, p. 987-990. Disponível em: https://www.sbgames.org/sbgames2018/files/papers/EducacaoFull/188190.pdf. Acesso em: 20 abr., 2019.

SOBREIRA, E. S. R.; VIVEIRO, A. A.; ABREU, J. V. V. Cultura maker e jogos digitais. In: MEIRA, L.; BLIKSTEIN, P. (Org.) Ludicidade, Jogos Digitais e Gamificação na Aprendizagem. Porto Alegre: Penso, 2020. (Coleção Tecnologia e Inovação na Educação Brasileira v. 3).

TODA, A. M. et al. Frameworks para o planejamento da gamificação em contextos educacionais - uma revisão da literatura nacional. RENOTE - Revista Novas Tecnologias na Educação, v. 16, n. 2, 2018. Disponível em:

https://www.seer.ufrgs.br/renote/article/view/89240/51485. Acesso em: 05 maio, 2019.

TODA, A. M.; SILVA A. P.; ISOTANI, S. Desafios para o planejamento e implantação da gamificação no contexto educacional. RENOTE - Revista Novas Tecnologias na Educação, v. 15, n. 2, 2017. Disponível em: https://www.seer.ufrgs.br/renote/article/view/79263/46157. Acesso em: 12 abr., 2019.

VIANNA, Y.; MEDINA, B.; TANAKA, S. Gamification, Inc: como reinventar empresas a partir de jogos. Rio de Janeiro: MJV, 2013.

VIEIRA, M. C. L.; ANDRADE, A. F. Estratégias e desafios para o uso da lousa digital interativa por meio de metodologias ativas. In: Workshops Congresso Brasileiro de Informática na Educação, Brasília, 2019. Anais (...). Brasília: Sociedade Brasileira de Computação, 2019, p. 701-710, 2019. Disponível em: https://www.brie.org/pub/index.php/wcbie/article/view/9019/6563. Acesso em: 12 abr., 2020.

VYGOTSKY, L. S. A formação social da mente: o desenvolvimento dos processos psicológicos superiores. 6. ed. São Paulo: Martins Fontes, 1998. 
WERBACH, K.; HUNTER, D. The gamification toolkit: dynamics, mechanics, and components for the win. Philadelphia: Wharton School Press, 2015.

Recebido em agosto de 2020.

Aprovado em novembro de 2020. 